\title{
PENENTUAN PARAMETER TERMODINAMIKA PEMBENTUKAN KOMPLEKS INKLUSI GLIMEPIRID-BETASIKLODEKSTRIN
}

\author{
Fitrianti Darusman, Endah Rahayu
}

Prodi Farmasi, FMIPA, Universitas Islam Bandung, Bandung, Jawa Barat, Indonesia

\begin{abstract}
Abstrak
Glimepirid merupakan obat antidiabetika oral golongan sulfonilurea generasi ketiga yang termasuk dalam Biopharmaceutical Classification System (BCS) kelas II dengan sifat kelarutan praktis tidak larut dalam air sehingga dapat ditingkatkan kelarutannya dengan pembentukan kompleks inklusi menggunakan senyawa turunan siklodekstrin yaitu betasiklodekstrin yang memiliki rongga toroidal dengan bagian dalam bersifat hidrofobik dan bagian luar bersifat hidrofilik. Penelitian ini dilakukan untuk menentukan harga tetapan stabilitas kompleks berdasarkan parameter termodinamika $(\Delta \mathrm{H}, \Delta \mathrm{G}$, dan $\Delta \mathrm{S})$ pada proses pembentukan kompleks inklusi glimepirid-betasiklodekstrin. Penelitian dilakukan dalam dapar asetat $\mathrm{pH} 6,2$ dan dapar fosfat $\mathrm{pH} 7,4$ pada suhu $32^{\circ}, 37^{\circ}$ dan $42^{\circ} \mathrm{C}$. Hasil penelitian menunjukkan bahwa glimepirid dapat berinteraksi membentuk kompleks inklusi dengan betasiklodekstrin. Interaksi antara glimepirid dengan betasiklodekstrin pada $\mathrm{pH}$ 6,2 berlangsung secara eksotermik $(\Delta \mathrm{H}<0)$, proses terjadi secara spontan $(\Delta \mathrm{G}<0)$ dan terjadi peningkatan ketidakteraturan sistem $(\Delta \mathrm{S}$ positif). Pada $\mathrm{pH} 7,4$ interaksi berlangsung secara eksotermik, proses terjadi secara spontan $(\Delta G<0)$ dan terjadi penurunan ketidakteraturan $\operatorname{sistem}(\Delta \mathrm{S}$ negatif).
\end{abstract}

Kata kunci : glimepirid, betasiklodesktrin, kompleks inklusi, termodinamika.

\section{DETERMINATION OF THERMODYNAMIC PARAMETERS FORMATION OF GLIMEPIRIDE-BETACYCLODEXTRIN INCLUSION COMPLEXES}

\author{
Fitrianti Darusman, Endah Rahayu \\ Prodi Farmasi, FMIPA, Universitas Islam Bandung, Bandung, West Java, Indonesia
}

\begin{abstract}
Glimepiride is a third-generation oral antidiabetika of sulfonylureas belonging to class II Biopharmaceutical Classification System (BCS) with solubility practically insoluble in water so that it can be increased solubility by formation of inclusion complex using cyclodextrin derivative compound ie betacylodextrin having inner toroidal cavity hydrophobic and the outside is hydrophilic. This study was conducted to determine the value of complex stability constants based on thermodynamic parameters $(\Delta \mathrm{H}, \Delta \mathrm{G}$, and $\Delta \mathrm{S})$ in the process of forming inclusion complexes of glimepiride-betacyclodextrin. The study was conducted in acetate buffer $\mathrm{pH} 6.2$ and phosphate buffer $\mathrm{pH} 7.4$ at $32^{\circ}, 37^{\circ}$ and $42^{\circ} \mathrm{C}$. The results showed that glimepiride can interact to form inclusion complexes with betacyclodextrin. The interaction between glimepiride with betacyclodextrin at $\mathrm{pH} 6.2$ takes exothermic $(\Delta \mathrm{H}<0)$, the process occurs spontaneously $(\Delta \mathrm{G}<0)$ and there is an increase in system irregularity $(\Delta \mathrm{S}$ positive $)$. At $\mathrm{pH} 7.4$ the interaction takes place exothermically, the process occurs spontaneously $(\Delta \mathrm{G}<0)$ and there is a decrease in system irregularities ( $\Delta \mathrm{S}$ negatives).
\end{abstract}

Keywords : glimepiride, betacyclodextrin, inclusion complexes, thermodynamic. 


\section{Pendahuluan}

Siklodekstrin adalah senyawa oligosakarida siklis mengandung sekurangkurangnya 6 unit D-(+)-glukopiranosa yang berikatan pada ikatan glikosida $\alpha-1,4$ dan mempunyai bentuk toroidal (rongga), dengan bagian dalam bersifat hidrofobik dan bagian luar bersifat hidrofilik. Terdapat tiga jenis siklodekstrin, yaitu alfa, beta dan gamma-siklodekstrin yang masing-masing terdiri dari enam, tujuh dan delapan glukosa dengan dimensi rongga dan kelarutan dalam air yang berbeda. Berdasarkan diameter dan kedalaman rongga siklodekstrin, alfa-siklodekstrin dapat membentuk kompleks dengan senyawa yang mempunyai berat molekul rendah atau senyawa rantai samping alifatis, beta-siklodekstrin dapat membentuk kompleks dengan senyawa aromatik atau heterosiklis, dan gammasiklodekstrin dapat membentuk kompleks dengan senyawa makromolekul dan steroid (Patil, 2008, Khan, 2013).

Kemampuan siklodekstrin untuk membentuk kompleks inklusi dengan senyawa guest dipengaruhi oleh dua faktor yaitu ukuran relatif rongga siklodekstrin terhadap ukuran molekul guest dan interaksi termodinamika yang terjadi antara molekul guest, siklodekstrin dan pelarut. Kompleks inklusi yang terbentuk dapat memperbaiki kelarutan, disolusi, stabilitas dan bioavailabilitas molekul guest dalam hal ini obat, serta dapat mengurangi iritasi lokal pada saluran cerna (Khan, 2013).

Salah satu obat yang dapat ditingkatkan kelarutannya dengan pembentukan kompleks inklusi adalah glimepirid menggunakan senyawa turunan siklodekstrin yaitu betasiklodekstrin. Glimepirid merupakan obat antidiabetika oral golongan sulfonilurea generasi ketiga yang termasuk dalam BCS kelas II dengan sifat kelarutan praktis tidak larut dalam air (Sweetman, 2009).
Pada penelitian sebelumnya, terbukti bahwa interaksi glimepirid dengan betasiklodekstrin mampu meningkatkan kelarutan glimepirid. Kelarutan glimepirid meningkat dengan semakin meningkatnya konsentrasi betasiklodekstrin (Darusman, Ulfa, 2017). Hal ini sejalan dengan hasil karakterisasi menggunakan Differential Scanning Calorimetry (DSC), difraksi sinar-X (PXRD) dan Fourier TransformInfra Red (FT-IR) yang menunjukkan adanya interaksi kompleks inklusi antara glimepirid dengan betasiklodekstrin serta uji kelarutan jenuh dan laju disolusi yang menunjukkan peningkatan laju disolusi glimepirid dalam kompleks inklusi dengan betasiklodekstrin dibandingkan glimepirid murni (Darusman, Silviyaturrohmah, 2017).

Kompleks inklusi yang terbentuk antara glimepirid dengan betasiklodekstrin didasarkan pada kemampuan obat untuk berasosiasi dan berdisosiasi secara berkesinambungan pada rongga betasiklodekstrin. Kemampuan molekul obat untuk berasosiasi dan berdisosiasi sehingga mencapai kesetimbangan dapat dilihat dari harga tetapan stabilitas kompleks (Shimpi dkk., 2005).

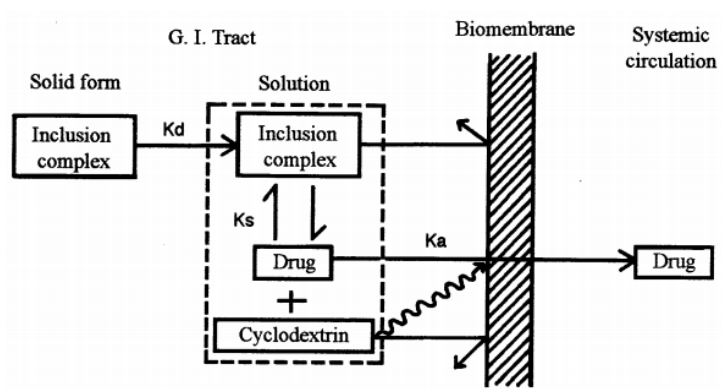

Gambar 1. Mekanisme absorbsi obat yang melibatkan kompleksasi siklodekstrin (Uekama dan Otagiri, 1987)

Penelitian ini bertujuan untuk menentukan parameter-parameter termodinamika meliputi energi bebas $(\Delta \mathrm{G})$, entalpi $(\Delta \mathrm{H})$, dan entropi $(\Delta \mathrm{S})$ pada proses pembentukan kompleks inklusi glimepiridbetasiklodekstrin sehingga mekanisme 
interaksi keduanya dapat diketahui dan dipahami. Hal ini menjadi penting karena di dalam tubuh obat tidak dapat diserap ketika masih dalam bentuk kompleks dengan siklodekstrin.

\section{Metode}

Alat

Timbangan analitik (Mettler Toledo AG204), vortex mixer (Thermo Scientific), shaker waterbath (GFL 1092), pH-meter, magnetic stirrer-hot plate (merk Thermo scientific) dan spektrofotometer UV (Shimadzu UVmini-1240).

\section{Bahan}

Glimepirid (Glenmark, India), betasiklodekstrin (Roquette), dinatrium hidrogen fosfat $\left(\mathrm{Na}_{2} \mathrm{HPO}_{4}\right)$ p.a dan kalium dihidrogen fosfat $\left(\mathrm{KH}_{2} \mathrm{PO}_{4}\right)$ p.a, asam asetat glasial $\left(\mathrm{CH}_{3} \mathrm{COOH}\right)$ p.a, natrium asetat $\left(\mathrm{CH}_{3} \mathrm{COONa}\right)$ p.a dan metanol p.a dan aquadest.

\section{Pembuatan Larutan Dapar}

Pembuatan larutan dapar asetat 0,01 $\mathrm{M}$ dengan $\mathrm{pH}$ 6,2 dan larutan dapar fosfat $0,01 \mathrm{M}$ dengan $\mathrm{pH}$ 7,4 (Isadiartuti, Suwaldi, 2007).

\section{Uji Kelarutan Glimepirid}

Dilakukan uji kelarutan glimepirid
dalam berbagai betasiklodekstrin $\quad\left(0 ; 2,5 \times 10^{-3} ; \quad 5 \times 10^{-3}\right.$; $7,5 \times 10^{-3}$; dan $\left.10 \times 10^{-3} \mathrm{M}\right)$ dilakukan dalam larutan dengan $\mathrm{pH} 6,2$ dan 7,4 pada suhu $32^{\circ}, 37^{\circ}$, dan $42^{\circ} \mathrm{C}$ (Isadiartuti, Suwaldi, 2007).

Larutan betasiklodekstrin dengan kadar dan $\mathrm{pH}$ tertentu sebanyak $5 \mathrm{~mL}$ dimasukkan ke dalam vial $10 \mathrm{~mL}$. Vial dimasukkan ke dalam shaker waterbath dan diatur suhunya sesuai dengan suhu percobaan. Setelah suhu percobaan

Korespondensi : Fitrianti Darusman efit_bien@yahoo.com tercapai, ke dalam vial dimasukkan glimepirid sekitar $50 \mathrm{mg}$ dan dikocok dengan kecepatan 50 rpm sampai terbentuk larutan jenuh. Larutan disaring menggunakan kertas Whatman dan ditentukan konsentrasinya dengan spektrofotometer ultraviolet pada panjang gelombang $228 \mathrm{~nm}$ yang telah diverifikasi. Percobaan dilakukan pada tiga kali replikasi $(\mathrm{n}=3, \mathrm{r}=2)$.

\section{Hasil}

Hasil uji kelarutan glimepirid dalam dapar asetat $\mathrm{pH}$ 6,2 dan $\mathrm{pH} \mathrm{7,4} \mathrm{dengan}$ beberapa konsentrasi betasiklodekstrin dapat serta variasi suhu dapat dilihat pada Gambar 2 dan Gambar 3.

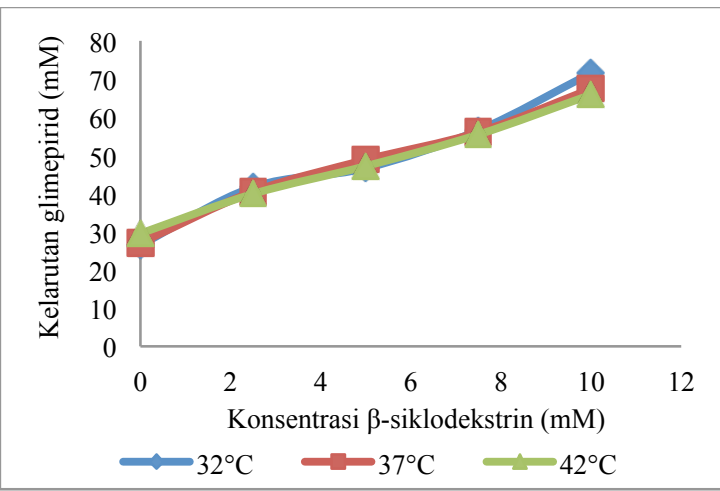

Gambar 2. Hasil uji kelarutan glimepirid dalam dapar asetat $\mathrm{pH}$ 6,2 dengan beberapa konsentrasi betasiklodekstrin pada suhu 32,37 dan $42^{\circ} \mathrm{C}$

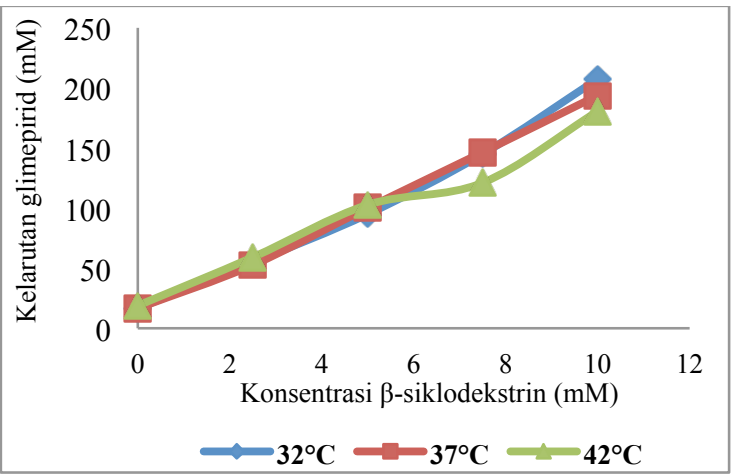

Gambar 3. Hasil uji kelarutan glimepirid dalam dapar fosfat $\mathrm{pH}$ 7,4 dengan beberapa konsentrasi betasiklodekstrin pada suhu 32,37 dan $42^{\circ} \mathrm{C}$ 
Harga tetapan stabilitas kompleks dapat dihitung dengan menggunakan persamaan dan harga tersebut, dapat dilihat pada Tabel 2 dan Tabel 3.

Tabel 1. Persamaan garis regresi hubungan antara kelarutan glimepirid (M) dengan konsentrasi betasiklodekstrin (M)

\begin{tabular}{ccc}
\hline \multirow{2}{*}{$\begin{array}{c}\text { Suhu } \\
\left({ }^{\circ} \mathbf{C}\right)\end{array}$} & $\mathbf{p H}$ & $\mathbf{6 , 2}$ \\
\hline 32 & $\mathrm{Y}=4,19474 \mathrm{x}+0,0276381$ & $\mathrm{Y}=18,8874+9,291 \times 10^{-3}$ \\
& $\mathrm{r}=0,9875$ & $\mathrm{r}=0,99439$ \\
\hline 37 & $\mathrm{Y}=3,85528 \mathrm{x}+0,0287087$ & $\mathrm{Y}=17,92936+0,01227$ \\
& $\mathrm{r}=0,9943$ & $\mathrm{r}=0,99883$ \\
\hline 42 & $\mathrm{Y}=3,528118 \mathrm{x}+0,0299718$ & $\mathrm{Y}=15,42452+0,01932$ \\
& $\mathrm{r}=0,9981$ & $\mathrm{r}=0,99059$ \\
\hline
\end{tabular}

Tabel 2. Harga tetapan stabilitas kompleks $(\mathrm{K})$ dan parameter termodinamika $(\Delta \mathrm{H}, \Delta \mathrm{G}$ dan $\Delta \mathrm{S}$ ) pada $\mathrm{pH} 6,2$

\begin{tabular}{|c|c|c|c|c|}
\hline \multirow[b]{2}{*}{$\mathbf{T}\left({ }^{\circ} \mathbf{K}\right)$} & \multirow{2}{*}{$\mathrm{K}(\mathrm{M})^{-1}$} & \multicolumn{3}{|c|}{ Parameter Termodinamika } \\
\hline & & $\Delta \mathrm{H}(\mathrm{kal} / \mathrm{mol})$ & $\Delta \mathrm{G}(\mathrm{kal} / \mathrm{mol})$ & $\Delta S(\mathrm{kal} / \mathrm{mol})$ \\
\hline 305 & -47.5074 & -387.9331 & -2339.8314 & 6.3997 \\
\hline 310 & -47.0320 & -387.9331 & -2371.9957 & 6.4002 \\
\hline 315 & -46.5621 & -387.9331 & -2403.9571 & 6.4001 \\
\hline
\end{tabular}

Tabel 3. Harga tetapan stabilitas kompleks $(\mathrm{K})$ dan parameter termodinamika $(\Delta \mathrm{H}, \Delta \mathrm{G}$ dan $\Delta \mathrm{S}$ ) pada $\mathrm{pH} 7,4$

\begin{tabular}{|c|c|c|c|c|}
\hline \multirow[b]{2}{*}{$\mathbf{T}\left({ }^{\circ} \mathbf{K}\right)$} & \multirow[b]{2}{*}{$\mathrm{K}(\mathbf{M})^{-1}$} & \multicolumn{3}{|c|}{ Parameter Termodinamika } \\
\hline & & $\Delta \mathbf{H}(\mathrm{kal} / \mathrm{mol})$ & $\Delta \mathrm{G}(\mathrm{kal} / \mathrm{mol})$ & $\Delta \mathrm{S}(\mathrm{kal} / \mathrm{mol})$ \\
\hline 305 & -113.6482 & -13843.87388 & -2868.4303 & -35.9851 \\
\hline 310 & -86.3137 & -13843.87388 & -2745.9881 & -35.7996 \\
\hline 315 & -55.3481 & -13843.87388 & -2512.1573 & -35.9737 \\
\hline
\end{tabular}

\section{Pembahasan}

Uji kelarutan glimepirid masingmasing dilakukan dalam medium dapar asetat $\mathrm{pH} 6,2$ dan dapar fosfat $\mathrm{pH} 7,4$ pada suhu $32^{\circ}, 37^{\circ}$, dan $42^{\circ} \mathrm{C}$. Pemilihan $\mathrm{pH}$ ini didasarkan pada harga $\mathrm{pKa} 1$ glimepirid yaitu 6,2 (Depkes RI, 2014). Berdasarkan perhitungan dengan menggunakan persamaan Henderson Hasselbach, pada $\mathrm{pH}$ yang sama dengan $\mathrm{pKa}$ glimepirid yaitu 6,2 sekitar $50 \%$ glimepirid berada dalam bentuk tak terion, sedangkan pada $\mathrm{pH} 7,4$ jumlah glimepirid dalam bentuk tak terionkan sekitar 5\%. Perbedaan jumlah tak terion dari molekul guest akan mempengaruhi interaksi dengan rongga siklodekstrin yang bersifat hidrofob. Umumnya, molekul obat yang berada dalam bentuk terionisasi memiliki ikatan yang lemah terhadap siklodekstrin dibandingkan dengan bentuk tak terionisasi.

Dari kurva hasil uji kelarutan (Gambar 2 dan Gambar 3), perpotongan antara kurva dengan sumbu $\mathrm{Y}$ atau intercept menunjukkan konsentrasi glimepirid bebas dalam larutan dan harga slope menunjukkan kemampuan betasiklodekstrin membentuk kompleks dengan molekul glimepirid. Kurva hasil uji kelarutan glimepirid pada $\mathrm{pH}$ 6,2 dengan suhu $32^{\circ}, 37^{\circ}$ dan $42^{\circ} \mathrm{C}$ menunjukkan bahwa persamaan garis mempunyai harga intercept yang semakin meningkat dengan meningkatnya suhu. Hal ini terjadi pula untuk kelarutan glimepirid pada $\mathrm{pH} 7,4$. Fenomena ini menunjukkan bahwa kelarutan glimepirid mengikuti proses endotermik yaitu semakin meningkat suhu semakin meningkat pula kelarutan glimepirid bebas.

Harga slope kurva dengan $\mathrm{pH}$ 6,2 dan 7,4 pada suhu 32,37 dan $42^{\circ} \mathrm{C}$ semakin menurun dengan meningkatnya suhu, ini mengindikasikan bahwa kenaikan suhu menurunkan kemampuan glimepirid untuk membentuk kompleks dengan betasiklodekstrin. Hal ini disebabkan karena glimepirid bebas cenderung mudah larut (hidrofilik) sehingga menurunkan kemampuannya untuk masuk/inklusi ke dalam rongga betasiklodekstrin. (Isadiartuti, Suwaldi, 2007).

Dari data Tabel 2 dan Tabel 3 menunjukkan bahwa baik pada $\mathrm{pH} 6,2$ maupun 7,4 adanya kenaikan suhu menyebabkan penurunan harga tetapan stabilitas kompleks (K). Tanda negatif pada $\mathrm{K}$ merupakan harga mutlak yang menunjukkan bahwa tidak terjadinya disosiasi kompleks. Harga $\mathrm{K}$ semakin menurun dengan adanya peningkatan suhu. Hal ini mengindikasikan bahwa kompleks inklusi yang terbentuk semakin tidak stabil sehingga interaksi antara glimepirid dengan 
betasiklodekstrin menjadi mudah lepas (Isadiartuti, Suwaldi, 2007).

Dengan membandingkan data pada Tabel 2 dan Tabel 3 juga dapat dilihat bahwa peningkatan $\mathrm{pH}$ dari 6,2 menjadi 7,4 untuk suhu percobaan yang sama, memberikan harga tetapan stabilitas kompleks (K) yang semakin kecil. Pada $\mathrm{pH}$ 7,4 jumlah glimepirid dalam bentuk terion lebih besar daripada $\mathrm{pH}$ 6,2. Besarnya jumlah molekul yang terion ini mempengaruhi kemampuan glimepirid untuk memasuki rongga betasiklodekstrin. Semakin besar jumlah glimepirid yang terion maka semakin hidrofilik dan kompleks yang terbentuk menjadi kurang stabil, karena molekul glimepirid cenderung keluar dari rongga betasiklodekstrin. Hal ini membuktikan bahwa $\mathrm{pH}$ lingkungan menentukan kemampuan pengikatan guest pada rongga siklodekstrin.

Dari data harga tetapan stabilitas kompleks $(\mathrm{K})$ dibuat grafik hubungan $1 / \mathrm{T}$ terhadap Ln K. Hasil percobaan pada $\mathrm{pH}$ 6,2 diperoleh persamaan garis : $\mathrm{Y}=$ $195,2356 \mathrm{x}+3,220998$ dengan $\mathrm{r}=0,99986$, sedangkan pada $\mathrm{pH} 7,4$ diperoleh persamaan garis : $\mathrm{Y}=6967,223897 \mathrm{x}-$ 18,07468 dengan $r=0,98850$. Dari data persamaan garis tersebut dapat dihitung parameter-parameter termodinamika $(\Delta \mathrm{H}$, $\Delta \mathrm{G}$ dan $\Delta \mathrm{S})$.

Entalpi $(\Delta \mathrm{H})$ menyatakan panas yang dilepaskan atau diabsorpsi jika satu mol zat terlarut dilarutkan dalam suatu pelarut dalam jumlah besar (Sinko, 2011). Dari hasil percobaan baik dengan $\mathrm{pH}$ 6,2 maupun $\mathrm{pH} 7,4$ diperoleh harga entalpi dengan tanda negatif yang menunjukkan bahwa proses pelarutan berlangsung secara eksotermik. Interaksi yang terjadi antara glimepirid dengan betasiklodekstrin terutama berupa interaksi hidrofobik dengan harga $\Delta \mathrm{H}$ pada $\mathrm{pH} 6,2$ sekitar 0,4 kkal dan $\mathrm{pH} 7,4$ sekitar 14 kkal.

Energi bebas $(\Delta G)$ menunjukkan kecenderungan suatu materi untuk berubah (Sinko, 2011). Harga perubahan energi bebas $(\Delta \mathrm{G})$ baik pada $\mathrm{pH} 6,2$ maupun 7,4 mempunyai harga negatif yang menunjukkan bahwa proses pembentukan kompleks berlangsung secara spontan. Hal ini disebabkan karena materi cenderung berubah menjadi tidak stabil akibat peningkatan suhu. Kompleks inklusi semakin tidak stabil akibat terjadi deformasi struktur kisi kristal sehingga ikatannya menjadi mudah terganggu dan merenggang karena peningkatan suhu akibatnya obat menjadi mudah lepas (Isadiartuti, Suwaldi, 2007).

Entropi $(\Delta \mathrm{S}) \quad$ menunjukkan ketidakteraturan sistem (Sinko, 2011). Pada percobaan menggunakan dapar asetat $\mathrm{pH}$ 6,2 didapatkan harga $\Delta S$ dengan tanda positif yang menunjukkan adanya peningkatan ketidakteraturan sistem. Hal ini menunjukkan bahwa sistem semakin tidak teratur sehingga obat semakin mudah memasuki rongga betasiklodekstrin yang disebabkan oleh banyaknya jumlah glimepirid yang tak terionisasi yaitu sekitar $50 \%$.

Sistem air yang teratur mengelilingi molekul glimepirid menjadi tidak teratur karena glimepirid masuk ke dalam betasiklodekstrin. Kondisi ini tidak disukai karena terjadi gaya tolak menolak polarnonpolar antara molekul air dengan bagian dalam rongga siklodekstrin sehingga kondisi ini dengan cepat diganti oleh adanya molekul guest yang bersifat kurang polar dibandingkan molekul air. Pembentukan kompleks dipengaruhi oleh pelepasan molekul air dari rongga siklodekstrin, rendahnya pelarutan obat dan interaksi antara molekul guest dan siklodekstrin dalam bentuk ikatan non kovalen sehingga di bawah kondisi fisiologis tubuh kompleks guestsiklodekstrin mudah sekali terdisosiasi.

Sedangkan, pada percobaan menggunakan dapar fosfat $\mathrm{pH} 7,4$ harga $\Delta \mathrm{S}$ yang diperoleh memiliki tanda negatif. Hal ini menunjukkan bahwa sistem semakin teratur sehingga obat sulit memasuki rongga betasiklodekstrin yang disebabkan oleh banyaknya jumlah glimepirid yang terionisasi yaitu sekitar 94\%. 


\section{Simpulan}

Dari hasil penelitian yang telah dilakukan dapat disimpulkan bahwa interaksi glimepirid membentuk kompleks inklusi dengan betasiklodekstrin :

- berlangsung secara eksotermik $(\Delta \mathrm{H}<0)$,

- interaksi terutama melibatkan interaksi hidrofobik,

- berlangsung secara spontan $(\Delta G<0)$,

- terjadi peningkatan ketidakteraturan sistem ( $\Delta$ S positif) pada $\mathrm{pH} 6,2$ sehingga glimepirid mudah memasuki rongga betasiklodekstrin.

- terjadi penurunan ketidakteraturan sistem ( $\Delta \mathrm{S}$ negatif) pada $\mathrm{pH} \quad 7,4$ sehingga sistem semakin teratur dan glimepirid sulit memasuki rongga betasiklodekstrin

\section{Daftar Pustaka}

1. Darusman, Fitrianti dan Ulfa Siti, 2017, Pengaruh Konsentrasi Betasiklodekstrin Terhadap Kelarutan Glimepirid, Jurnal Ilmiah Farmasi Farmasyifa Vol.1 No.1: 17-25.

2. Darusman, Fitrianti dan Silviaturrohmah, 2017, The Formation of Inclusion Complexes of Glimepiride-Betacyclodextrin to Increase Solubility and Dissolution Rate, Prosiding ICPAPS UGM.

3. Depkes RI. (2014). Farmakope Indonesia Edisi Kelima. Dirjen POM RI, Jakarta : 492.

4. Isadiartuti, Dewi dan Suwaldi. (2007). Termodinamika Pembentukan Kompleks Inklusi Fenobarbitalhidroksipropil - $\beta$-Siklodekstrin. Majalah Farmasi Indonesia. 18 (22): 57-62.

5. Khan, A.N., Durakshan, M. (2013). Cyclodextrin: An Overview. IJBIO. 02 (06): 858-865.

6. Shimpi, S., Chauhan, B., Shimpi, P., (2005). Cyclodextrin Application in Different Routes of Drug

Korespondensi : Fitrianti Darusman efit_bien@yahoo.com
Administration, Acta Pharm, 55, 139155.

7. Sinko, Patrick J. (2011). Farmasi Fisika \& Ilmu Farmasetika Martin Edisi 5, alih bahasa, Joshita Djajadisastra, Amalia H. Hadinata. Jakarta : EGC

8. Patil, A.L., Aleem, O.M., Pore, Y,V., Kuchekar, B.S., (2008). Cyclodextrin in Pharmaceticals: An Overview. Diakses dalam www.pharmainfo.net/pharma-studentmagazine/cyclodextrinpharmaceuticals-overview- 0 pada hari Senin, 26 Desember 2016, pukul 17.57 WIB.

9. Sweetman, S.C. (2009). Martindale 36 The Complete Drug Reference. London: The Pharmaceutical Press

10. Uekama, K., Otagiri, M., (1987). Cyclodextrins in drug carrier systems. CRC Crit. Rev. Ther. Drug Carrier Syst. 3, 1-40. 